\title{
Path dependence: some introductory remarks ${ }^{1}$
}

\section{Lars Magnusson and Jan Ottosson}

I

The notion of path dependence has been discussed and utilized in various social sciences during the past two decades. The increasing interest in institutions and economic growth has certainly been important in this respect. Also, the role of technology as well as the discussion of various heterodox aspects of economic evolution might also be mentioned. More specifically, the rise of historical institutionalism and the interest in institutionalism in several social sciences has led to a number of applications of path dependence in various social sciences. As Gartland (2005, p. 687) rightly observes, there seem to be several applications of path dependence in various social sciences outside economics, but relatively few references among economists towards other social science's application of this concept. We can see two dangers with this development. First, the rising number of empirical applications might lead to an uncritical use of the notion of path dependence. Second, we agree with Gartland that the ignorance among some economists to acknowledge important research regarding path dependence in other social sciences might lead to two parallel discussions.

In relation to Hodgson's argument (1993) regarding the risk of economic imperialism into other social sciences, we believe that all social sciences - including economics - might gain from current discussions of path dependence broadly illuminated from various angles. Therefore it seems appropriate to further discuss the topic of path dependence from various aspects in this Edward Elgar Companion on path dependence. The aim of this volume is therefore to illustrate how various disciplines have used the concept of path dependence and to illuminate studies within these fields. Also, one further aim is to discuss the often used concept of path dependency and analyse the possibilities as well as the limitations of its applications.

The term of path dependence has been attributed to several older economists. Gartland (2005) suggest that Schumpeter was an innovative 
researcher in this respect when arguing that history was one important aspect when studying economics. This was later acknowledged by Rosenberg (1994) when he argued for using path dependence as a tool of such a method. Also, recent research has identified scholars such as Menger and Veblen (1915), among others, who were associated with an early use of path dependence even though they did not use the concept (Martin and Sunely, 2006, p. 397). Arrow's important discussion of the historiographic records of path dependence also points to the works of Cournot in the 1830 s in terms of increasing returns, also acknowledging Veblen's work regarding path dependence (Arrow, 2000, pp. 173, 175). Douglas Puffert also listed Veblen (1915), Frankel (1955), Kindleberger (1964) and David (1975) as especially important scholars in terms of emphasizing early aspects of path dependence, especially interrelatedness of the technology and economic history (Puffert, 2003; see also Hodgson, 1998, on the early influences on path dependence).

Within the field of technology of history, path dependence has been used as a tool of understanding processes of lock-in and changing technologies. Initially, this was used as alternative explanations of choices of technology which differed from standard neoclassical explanations. Nathan Rosenberg, being immensely influential within this field, argued in the volume Exploring the Black Box, published in 1994, that ongoing technological progress must be understood against earlier technological experiences. Magnusson (2001) has elsewhere interpreted this as containing elements of path dependence, since earlier technological breakthroughs at least to some extent may limit choices available for actors. According to this tradition of thought, historical paths influence and limit the scope of actors involved in emerging technologies. Some well-known stylized examples of this have been gas engines and railway gauges. In a recent application of path dependence in economic history, Peter Scott (2001; 2006) has argued that the decline of the British coal industry was closely related to the lock-in effect of suboptimal technology.

Further, Magnusson argued that two types of notions of path dependence within the history of technology have emerged. If the Rosenberg interpretation might be called a 'weak' version of path dependence, 'strong' versions of path dependence can be found among scholars such as Bijker, Hughes and Latour within the systems of technology approach. They argue not only that the actual choices available are limited owing to earlier historical experiences, but that the cognitive search progress is influenced by these earlier historical events. The notion of large technical systems can be seen as one of the most influential schools of thought within this 'strong version' field, where Thomas Hughes and Bijker are among the most influential scholars. 


\section{The Contributions of Paul David}

There is, however, no doubt about the pioneering role of Paul David and Brian Arthur, who were the first to initiate a discussion of the relevance of path dependency, in the 1980s and 1990s. They used path dependence in their original works as a description of lock-in effects in terms of technology. Arrow also points to the early work of Paul David from 1971, along with Atkinson and Stiglitz's work on technology from 1969 (Arrow, 2000, p. 175). One key factor was the recognition of non-ergodic systems, emphasizing that it was hard to shake off earlier history, as discussed by Martin and Sunley (2006). Paul David (1985) used the example of the QWERTY keyboard to illustrate how choices of new technology were influenced by forces other than mere optimal choices on a perfect market. The basic argument of this influential article was that the organization of the letters on the keyboard was a result of small chance events, thus giving rise to a standard despite the competitor Dvorak keyboard layout being more optimal, according to David. This argument was further elaborated in several publications by David (David, 1990, 1994; and David and Thomas, 2003) to follow.

In general terms, David has argued that it is not possible to understand why certain technologies have been chosen without analysing earlier events and their impact on existing technology choices. This has been discussed in terms of 'history matters'. David discusses three reasons why such dependencies occurred. First, cognitive selections developed over time can be seen as shaping a collective memory, being one part of reducing choices for actors due to historical reasons. Second, firm-specific investments might also be a part of such path dependence, sensitive to earlier historical events. The third reason relates to strong interrelatedness in complex organizations, which also would include technological interrelatedness (Magnusson, 2001; Martin and Sunley, 2006). As Magnusson has argued, this is certainly a version of path dependence which can be seen as more closely linked to the 'strong' notion of path dependence.

Also, it is indeed a far more general definition compared with Rosenberg's interpretation regarding technical systems and their process of transformation. Path dependence in this interpretation can be regarded as being sensitive to random choices at the beginning of a process, and where these random small steps will be reinforced even further. Also, in an important article by Antonelli (2006), the role of path dependence and localized technical change and innovations is discussed in terms of a framework, or a tool, for explaining economic dynamics by going beyond the static analysis of general equilibrium.

In an influential article from 2001 (also republished in 2007), David 
discussed the heated debate concerning path dependence, as well as the various applications. It is worth noticing that Hodgson suggest that this is one of the most important articles regarding path dependence (Hodgson, 2007, p. 14). David suggests the following definition:

Path-dependence, as I wish to use the term, refers to a dynamic property of allocative processes. It may be defined either with regard to the relationship between the process dynamics and the outcome(s) to which it converges, or the limiting probability distribution of the stochastic process under consideration. (David, 2007, p. 123; original emphasis)

Also, David argues that a positive definition of path dependence might be formulated in the following way: 'A positive definition: A path dependent stochastic process is one whose asymptotic distribution evolves as a consequence (function of) the process's own history' (David, 2007, p. 125). By giving path dependence a more general definition, this also had important implications for the role of lock-in effects, as further noted by David.

Path dependent systems - which have a multiplicity of possible equilibria among which event-contingent selections can occur - may thus become locked in to attractors that are optimal, or that are just as good as any others in the feasible set, or that take paths leading to places everyone would wish to have been able to avoid, once they have arrived there. (David, 2007, p. 131)

In line with the above stated definitions, David and Thomas have argued that path dependence should be considered as a systematic feature. They especially emphasize the role of path dependence in a dynamic system: 'of a system whose motion remains under the influence of conditions that are themselves the contingent legacies of events and actions in its history' (David and Thomas, 2003, p. 15). In this interpretation of path dependence it is not useful to analyse all economic phenomena in a path-dependence influenced analysis. They suggest that several problems can rather be better analysed by a traditional demand and supply analysis. However, David and Thomas suggest that to what extent path dependence occurs in economic life is an empirical problem. They argue strongly against the idea of path dependence as a theory. Rather, it should be seen 'as a label that refers to particular dynamic properties that characterise some but not all resource allocation processes' (David and Thomas, 2003, p. 17). They further mention that it can be defined as a process associated with the dynamic processes and the outcome or the limitation of possible actions available within a dynamic system.

Thus, a dynamic system could be characterized by being a pathindependent system, where the initial conditions will not hamper future development. The case of path-dependent systems could rather be defined 
as: 'a path-dependent stochastic system is one in which the system's asymptotic distribution evolves as a consequence (function of) the process's own history' (David and Thomas, 2003, p. 18).

The authors also argue that path-dependent processes are not only a matter of identifying suboptimal choices, due to static inefficiencies. They see, for example, markets with strong network externalities as particularly sensitive to initial historical shaping events, but they also emphasize that in some instances, path dependence might also be a mechanism that can be important in promoting dynamic efficiency. The analysis of positive feedback phenomena are at the centre of both such approaches (David and Thomas, 2003, p. 26).

To sum up, this interpretation of path dependence suggests that only some economic issues are suitable for this label. Traditional demandsupply explanations are in fact more useful in explaining several economic phenomena. On the other hand, for specific empirical problems, for example, in industries with network externalities, path dependence can be used as a label or tool to study positive feedback phenomena. Such phenomena can be both negative to its character - hampering economic dynamics - or positive - by enhancing successful economic development even further.

According to our view, this new development of the concept of path dependence may intuitively be promising, since the issue of institutional change might be included in such a definition. However, there might be a risk of adding little explanatory value with this broad concept of path dependency, owing to the obvious risk of explaining every dynamic process - successful or not - as a path-dependent process. This opens up path dependency to types of explanations that are very general.

\section{Brian Arthur and Increasing Returns}

Brian Arthur discussed, with regard to the technology interpretation, the mechanisms that created path dependence and the interrelationship with positive feedbacks in the economy in terms of increasing returns. The notion of increasing returns was especially important within knowledgebased industries, according to Arthur. In contrast to diminishing returns, increasing returns made it possible to reach several equilibria. This made it possible to better understand why the market choice was not necessarily the only optimal solution. The importance of initial random effects, 'small effects' as Arthur put it in a seminal article in 1989, and the locked-in path once chosen, were essential in Arthur's discussion of path dependence and increasing returns.

Important factors behind these mechanisms were positive learning 
effects (on the supply side, according to Puffert), large initial investments, economies of scope, externalities (demand side - Puffert, 2003; see also Katz and Shapiro, 1994), and regional external economies. The last factor was emphasized by Arthur, where the initial location decision was crucial for the future lock-in effects in terms of agglomerative effects (Magnusson, 2001, p. 110). Another empirical example used by Arthur, widely cited, criticized and discussed afterwards, was the choice between the videocassette recorder (VCR) systems - VHS and Betamax.

Both David and Arthur emphasized the case of technology, and the importance of chance or initial events. Also, both authors claimed that the notion of path dependence was indeed important with respect not only regarding the technology in itself, but also the whole economy. However, one difference between the two authors which Puffert (2003) points out is that David can be seen as one representative of a long tradition of technological interrelatedness, while Arthur in the early articles on path dependence is influenced by mathematical economics.

\section{The Liebowitz-Margolis Criticism of Path Dependence}

In several highly critical articles and books, Liebowitz and Margolis (for example, 1995) have forcefully argued that most of these phenomena discussed within the path dependence discussion could be analysed by standard neoclassical economics. In one important work they discuss three types of path dependence, where the difference between these types is the information available for the agent. Within the first degree of path dependence a second-rate choice might be rational and optimal owing to the fact that the agent is aware of the costs attained when abandoning an earlier path. The second degree of path dependence can be seen as a higher degree of incomplete information in a choice situation. An economic agent can later be aware of the incomplete information at the time of the earlier choice.

However, according to Liebowitz and Margolis, that is not a case of inefficient solution owing to the actual loss of relevant information. The third case of path dependence is where the economic actor is well aware of more optimal choices, but still prefers the path-dependent choice. The authors thus conclude that the two first mentioned cases of path dependence can be seen as rational choices, best analysed with standard neoclassical tools. The third option was seen as being very rare and not worthwhile concentrating on.

We have in earlier works (Magnusson and Ottosson, 1996) discussed these three degrees of path dependence and argued it may not be entirely clear that the first two degrees of path dependence might be analysed properly within the framework of neoclassical economics, since it may not be 
clear what the actual cost of abandoning earlier paths of choice might be for the agent. Also, in a situation with radical uncertainty, arguments regarding rule-following might still be more fruitful. Another point of discussion that we highlighted was the possibility that the rule-following process and the process of obtaining and processing information might be socially influenced, thereby restricting actual choices, thus creating path-dependent choices. This argument in terms of genuine rule-following was developed by Vanberg (1988) and further extended by Rutherford (1994). This can be seen as a reference to the earlier mentioned 'strong' view of path dependence.

On the other hand, we pointed out the risks of totally denying the forceful criticism of Liebowitz and Margolis, also acknowledging the need for an ongoing discussion of the concept of path dependence. The ongoing discussion during this decade on these issues has developed in various directions. The answers to this criticism from Arthur and David have been extensive.

The second part of Liebowitz and Margolis's main criticisms on path dependence was built upon through empirical studies on the most cited empirical examples emphasized by David and Arthur. The case of QWERTY was heavily criticized as being misinterpreted. The choice of the QWERTY keyboard was, according to Liebowitz and Margolis, the most efficient choice, since the Dvorak keyboard represented underperforming technology. Also, the case of the VCR was also seen as an example of how efficient markets could adopt the most efficient technology. As noted earlier, Paul David answered this criticism in an important article in 2001.

A third position in this debate has been launched by Martin and Sunley (2006), concluding that both David's argument with regard to Liebowitz and Margolis as well as the interpretation by these authors of path dependence might be considered somewhat ambiguous. Several authors have recognized the different meanings of path dependence and lock-in when further interpreted by David and Arthur (Lawson, 1997). According to Martin and Sunley there is a difference between evolutionary economic systems and path dependence. In line with Witt (2003a; 2003b), they argue that an evolutionary economic system might be interpreted in much broader terms compared with the narrow concept of path dependence, despite the fact that some authors suggest that path dependence is the first-order concept in evolutionary economics. Indeed, Vromen (1995), as noted by Martin and Sunley, suggests that path dependence is only one aspect of selection as well as adaptive learning.

The third position in this debate points to the increasing literature on the role of choice, where rational choice and rule-following arguments have been among the most discussed topics, the path dependency discussion points to the importance of increasing our understanding of such 
processes of agent's choice (Ramstad, 1994; Rutherford, 1994; Vanberg, 1994). Within the tradition of Nelson and Winter (1982), several authors have emphasized that rule-following exists (Rutherford, 1994, p. 54). Also, such routines can be of importance during long periods of time, as discussed by Nelson and Winter. The role of uncertainty and the consequences for the economic actor's behaviour in terms of rule-following has been illuminated by Heiner (1983), North (1990; 2005) and Denzau and North (1994).

\section{Institutional Theory: North versus Anti-Determinism}

The debate regarding the role of history, lock-in effects and the acknowledgement of increasing returns also made clear that institutions and history did play an important role in terms of general economics, the initial articles by David and Arthur became important analytical component in Douglass North's work (1990; 2005). Why some nations were stuck in poverty while others prospered was seen as one important example of the existence of suboptimal behaviour directly affecting economic growth between various nations. Positive transaction costs, uncertainty, and actors forming organizations and institutions as rules of the game, made it possible to more directly explain the mechanisms behind different paths of economic growth. North (1990, p. 95) suggests that path dependence can only occur in certain situations when increasing returns and imperfect markets are at hand. North (2005) has further emphasized the role of culture in influencing choices made by economic agents.

The debate regarding the lock-in effect and the mechanisms that constitute paths chosen has also pointed to the notion of path dependence and change. Earlier studies by Thelen and Steinmo, Gersick and Setterfield discussed two types of processes of change. The first process was discussed in terms of punctuated equilibrium, where a sudden dramatic change radically broke earlier patterns of path dependence. A strong version of this explanation is preferred by Mahoney (2000), who argues that only a precise definition of path dependence is useful when understanding certain event chains with 'deterministic properties' (quoted from Streeck and Thelen, 2005; Mahoney, 2000, p. 507). Another example of scholars wanting a more precise definition of path dependence in this respect are Martin and Sunley $(2006 ; 2007)$, who have raised the issue that path dependence as an explanation might be lacking a more precise meaning within the field of economic geography. Similar argument has been raised by Page (2006).

The second process was discussed in terms of a slow continuous process of change, where attention was focused on incremental changes and learning in relation to adaption, see for example, North (1990), where he explains 
the latter as the most common one. In a more recent contribution Streeck and Thelen note 'the impoverished state of theorizing on issues of institutional change' (Streeck and Thelen, 2005, p. 1). They criticize the punctuated equilibrium model in its strong interpretations of drawing too heavily on exogenous shock types of explanations for not being able to explain processes of gradual change. On the other hand, they continue, recent approaches within the field of variety of capitalism type of explanations (Hall and Soskice) tend to emphasize institutional resiliency. However, according to Streeck and Thelen, such explanations seem to neglect possible explanations of institutional change. Rather, these theories 'regard ... almost all feedback within a system as positive and operating to maintain traditional structures' (Streeck and Thelen, 2005, p. 5). Also, scholars like Amable (2000) and Boyer (2005) have, inspired by the variety of capitalism literature, discussed institutional complementarities in terms of alternative approaches towards initial path-dependent conditions (see also Aoki, 2000, in this respect). Boyer, for example, discusses how such complementaries might be of special interest regarding the convergence-divergence debate (Boyer, 2005).

Paul Pierson's $(2000 ; 2004)$ discussion of institutions and path dependence as a tool of understanding the welfare state is seen as one example of a theory more helpful in explaining institutional resilience, but not satisfactory in understanding institutional change. Rather, Streeck and Thelen suggest that a more complex theory might give room for explanations open to processes of 'incremental change with transformative results' (Streeck and Thelen, 2005 , p. 9). Especially important engines of institutional changes are the difference between design processes of institutions and their implementation, respectively. Five models of gradual change of formal institutions (which differ from North's latest emphasis on informal institutions) are discussed, all examples of gradual change (see also Crouch and Farrell, 2004).

Close to development within political science and the role of path dependence, similar patterns of thought have emerged in political economy and transaction costs, as we have discussed elsewhere (see Magnusson and Ottosson, 2001). One of these lines of analysis, the notion of political transaction costs, is especially relevant in this context. Political transaction costs deal with actors trying to make decisions in complex and uncertain political spheres. The actors are seen as acting in the field of bounded rationality. Transaction costs are transferred from the element of real-world economics to the field of policy (Dixit, 1996; Olson, 2000; Williamson, 1996). Based on an extension of Williamson's model of transaction cost economics, Dixit suggested that the complexity, uncertainty, information impactedness, opportunism and asset specificity in a dynamic environment might be applied within the political world (Dixit, 1996; 
Dugger, 1993, might also be mentioned in this context). Owing to the incompleteness of contracts a difference emerges between policy outcomes and policy aims.

The main reason, according to Dixit, is the complexity of political contracts, since such contracts are even more incomplete. This results in higher transaction costs, but the consequences of these transaction costs are more problematic compared with the economic sphere, owing to the longer term involved in constitutional arrangements. Incomplete contracts within the field of constitution leave room for actors' opportunistic behaviour (Dixit, 1996, pp. 20-21). Dixit further argues that within the field of policy decisions, monitoring and incentives are more complex compared with the marketplace, since the costs of enforcement are higher. Further, the complexity of the principal-agent dilemma is illustrated through the existence of multilateral principal-agent relations within public administration. Within this tradition, the paths of implementation are also acknowledged as important, with government agencies as key actors owing to incomplete contracts, and multiple principal-agent relationships (Dixit, 1996, p. 56; Wilson, 1989, ch. 17).

As we have argued elsewhere (Magnusson and Ottosson, 2001), this can be discussed in light of the findings by Krueger (1996, pp. 169-218) regarding regulatory systems and the role of history in understanding regulated economies (Goldin and Libecap, 1994). The role of history might be better illuminated in understanding processes of policy outcomes in regulation of the economy, due to path-dependent patterns influencing implementation in such policy processes.

There are limits to applying political transaction costs in neoclassical designs (Magnusson and Ottosson, 1996; 2001). Instead, we have suggested elsewhere that it might be more fruitful to discuss such an approach within a more historically grounded framework with more specific pathdependent factors included in explaining dynamic types of processes available (Magnusson and Ottosson, 1996, p. 353).

\section{III}

To what extent is path dependence a useful concept in economics? As we have seen, there is no general agreement among scholars on this point. For example Liebowitz and Margolis (1995) argue that 'real' path dependence occurs extremely seldom in economic life and, consequently, the phenomenon might very well be discarded altogether. Irrational behaviour - to the extent it occurs - has no place in economics. Rather, the task of economics is to explain economic behaviour given a certain set of conditions (including the information available) which 'bounds' the individual to make 
specific choices in an economic world of more or less uncertainty. Hence, what in general seems to be 'irrational' behaviour must be understood in such a context of cognitive boundedness and lack of full information. Certainly, with such a strict definition of rationality it seems unlikely that much economic behaviour falls outside. To follow a 'path' or to stick to rule behaviour according to tradition is thus best understood as a consequence of high levels of uncertainty; the cost of breaking off from the traditional path can in some circumstances be too high. Hence, something we might call 'path dependence' or 'rule-following' of course occurs frequently in economic life (Rutherford, 1994). Moreover, it can be explained in a customary way from the maximizing and rational behaviour of the individual.

However, this does not exclude, of course, that path dependence of the first and second order (according to Liebowitz and Margolis's vocabulary) is an interesting phenomenon in the economic world. The high cost of information as well as high sunken costs of different kinds can make it very expensive indeed (and highly risky) to change one's behaviour. Moreover, such costs also create barriers of entry for those who seek to compete. In such an economic realm increasing returns of scale often occur, which also propel strong forces in favour of path dependence. Hence, the conclusion must be that 'path dependence' is still an interesting phenomenon and to understand how it is created must be of utmost important for economic science. Under which institutional constraints are path dependence (or rule-following) likely to occur? At which levels of cost? In which context of uncertainty can we expect path dependence to appear? What is the price for breaking with a path? Without doubt these are pertinent questions if one is to be able to understand economic behaviour and change (or perhaps, rather, the lack of it). Only a small proportion of our behaviour, for example, on the market can be explained as rational choices in a situation of perfect information (lemons). Not least the insistence by economists such as Stigler and Akerlof on how common situations of assymetrical information appear in a specific market has further emphasized this point. Rather, in many instances we follow the tradition and stick to a certain set of rules which seems to have served us well previously. We are not willing to undertake the cost - or are too lazy even to count the cost involved - to change our behaviour.

Economic institutions, according to North and others, can be regarded as rules (formal and informal). They are set to work by rational actors in circumstances where public choices have to be made. There are reasons to believe that the institutions we choose in order to solve such conflicts are to some extent determined by past experiences, the choices we have made in the past and given our (without doubt highly restrictive) knowledge of 
institutional alternatives and how they work in practice. This might help to explain institutional inertia as a general phenomenon, but also why we so often seem to acknowledge different institutional 'styles' or modes of governance, for example, varying among different countries. Without doubt there are different national systems or regulations which can only be understood in a context of path dependence. We recognize different 'varieties of capitalism', different models of welfare and labour market regulations, and so on. Hence the rules that define different institutions are historically created according to choices that are highly path dependent. We should then not be surprised to find specific and long trajectories of regulations with regard to specific goods and markets, for example, the American sugar (Krueger, 1996) or the European aeroplane industry (Ottosson, 2001).

However, individual choices are highly influenced by rule-following and path-dependent behaviour. As consumers we are often prone to follow certain rules of thumb when we feel that calculations are too costly or the outcome highly ambiguous. Also firms follow certain rules, or what Richard Nelson and Sidney Winter (1982) have called 'routines'. Past experience creates a pool of useful knowledge which can be used when individuals or firms confront a specific problem or are forced to make choices. Without doubt, behaviour on such a basis can very well be defined as 'path dependent'.

Growth processes occurring over time include path-determined aspects. Hence, increasing returns often help to create growth processes in certain sectors of the economy or with specific regional attributes which are stable over long periods of time. Past and sunken investments also contribute to such a process of 'first- and second-order' path dependence (once again according to Leibowitz and Margolis, 1995). Certain patterns of economic growth also lead to specific collective problems of choice which, in turn, lead to specific institutional solutions. These, in turn, probably even further enforce specific growth processes over time, including such spirals over positive and negative economic development which Douglass North speaks of (North, 1990). As such institutions give opportunity to diffuse different incentives among actors this even further enforces such spirals of 'good' or 'negative' development or specific part-determined growth processes.

It seems clear that path dependence can be a useful concept for economists when applied in such an open way. It can be a useful label in order to describe different forms of rule-following and when a given path is chosen instead of other or new alternatives. The next step is to analyse the specific circumstances and causes of why rule-following and path dependence occurred in the specific context. It can shed light both on why repetition and inertia is so common in human social and economic affairs, but also in which circumstances changes occur. When new information appears or when its 
price radically shifts downwards, a long historical path can suddenly be deserted. Big events and shocks from outside often force us to carry out calculations and make new choices. However, small incremental changes can also suddenly change the cost and price structure in a fashion which make new choices feasible and necessary. Hence, so-called punctuated equilibria as a consequence of shocks from outside are not the only way to understand and explain change. But there is no doubt that big events often stimulate people to think in new ways and make radically new choices. For all this, the concept of path dependence can be a useful tool for further analysis. However, it is not - perhaps to the disappointment of some radicals - an alternative to mainstream economic theory. Rather, in our view, it can be seen as a complement to the general economic analysis of phenomena such as choice and market behaviour. However, its radical implication is that it challenges the economists to pay more attention to the role of institutions and historical development. Hence, as the great economic historian John Clapham emphasized long ago, there is perhaps nothing genuinely wrong with analytical economics. However, its empty boxes must be filled with content in order to become really relevant as a social science.

\section{IV}

The application of path dependence has been widespread, which we have illustrated above, with examples from the history of technology, the rise of the welfare state as interpreted by Pierson (2000), and the use of path dependence in political economy. (See also Page, 2006, as well as Alexander, 2001.) Various applications can be found in several social sciences besides the above-mentioned cases: from economic geography, industrial relations (Howell, 2005), studies of Russia and the transition economies (Hedlund, 2005; see also Chavance and Magnin, 2002), within the field of business studies (see examples mentioned by Ebbinghaus in this volume), and financial economics, to economic history and detailed studies of coal mines in England, to medieval trade (Greif, 2006) and railway gauge (Puffert, 2002; see also Cowan, 1990, 1996). Also, one example from sociology is found in Goldstone (1998), as well as several examples from within the field of innovation studies (Langlois and Savage, 2001; Redding, 2002). In this volume we give some further insights into how various applications of path dependence have been used. The contributions in this volume suggest that there has been a development from applications of path dependence in the history of technology towards other fields of social science. The discussion has focused upon various types of definitions of path dependence (strong or weak type of definitions). Also, the application of the notion of path dependence has been 
discussed widely within some parts of social sciences. One further important aspect deals with various types of institutional stagnation versus institutional change. Such phenomena are discussed in the chapters that follow.

In Chapter 1 historian Bo Stråth critically examines the concept of path dependence from the viewpoint of scepticism towards structural explanations in understanding historical processes. In the second chapter economic historian Gary Libecap discusses path dependence from the viewpoint of political economy, political action by the state in land use and property right, with long-term implications for the farmers in the USA. Economic historian Lena Andersson-Skog discusses various applications of path dependence with reference to the example of the railway sector. From the viewpoint of economic geography, the important contributions, for example, by Krugman in relation to various explanations of economic agglomorations are discussed by Lagerholm and Malmberg. Examples from the political field of applications are presented by Öberg and Hallberg Adu, who argue that there is a need to further improve theories of evolution, while looking at stability and change within the same analytical frame. They especially discuss how various country patterns of polity and industrial relations can be interpreted by path dependence. Within the field of economic growth, and the interaction between science, technology and innovations, historian Hollingsworth discusses interaction processes against such a background with references to the French regulation school of thought together with historical institutionalism. Further, Hollingsworth discusses in detail how institutional environments influence organizations' innovativeness by studying major innovations in biomedical science, pointing to the role of organizational culture in this respect. Margolis discusses from the viewpoint as one of the leading critics against earlier interpretations of path dependence, but discusses other potential areas of using path dependence, as one part of analysing policy processes. In the final chapter Ebbinghaus interprets labour markets and the welfare state as especially interesting in using path dependence. Ebbinghaus also discusses institutional change in relation to path dependence and discusses the limits of path dependence in this respect.

The chapters presented in this volume illustrate the various interpretations of path dependence as one important common ground. Ranging from a principal and critical discussion of use of structural type of explanations towards more positive views of the potential of path dependence in new areas, such as the political economy and economic geography, there are some particular points of interest. First, one of the most forceful critics of path dependence within the field of technology suggest that path dependence might be potentially important within the field of political economy, owing to the differences between market and policy. In order to better explain economic policy outcomes, path dependence might be useful. 
Second, several authors comment upon the interrelation between stability and change, and how path-dependent types of explanations need to be further developed towards explaining patterns of change. Also, various levels of analysis in relation to path dependence have been raised as a point of particular interest, where not only micro- or macro-levels have been addressed, but also various middle-range theories. Third, the interaction between actor and structure in relation to the path dependence discussion has been addressed in various parts of this volume. As we have argued in this chapter, it is crucial to further discuss more precisely what type of notion of path dependence various applications are using. If the concept is not carefully defined from the viewpoint of a new area of application, the risk is obvious that the explanatory value of path dependence might be in danger. Instead, it is certain that there is a range of empirical fields which we can only address properly by using a clearly defined path-dependence type of explanations. The discussions in this volume also make it clear that using path dependence uncritically in various empirical areas may not achieve such a development.

\section{NOTE}

1. We would especially like to thank Geoffrey Hodgson for most valuable comments on an earlier version of this chapter.

\section{REFERENCES}

Alexander, G. (2001), 'Institutions, path dependence and democratic consolidation', Journal of Theoretical Politics, 13 (3), 249-270.

Amable, B. (2000), 'Institutional complementarity and diversity of social systems of innovation and production', Review of International Political Economy, 7, 645-87.

Antonelli, C. (2006), 'Path dependence, localised technological change, and the quest for dynamic effiency', in C. Antonelli, D. Foray, B.H. Hall and W.E. Steinmueller (eds), New Frontiers in the Economics of Innovation and New Technology: Essays in Honour of Paul A. David, Cheltenham, UK and Northampton, MA, USA: Edward Elgar, pp. 51-69.

Aoki, M. (2000), Information, Corporate Governance, and Institutional Diversity: Competitiveness in Japan, the USA, and the Transitional Economies, Oxford: Oxford University Press.

Arrow, K. (2000), 'Increasing returns: historiographic issues and path dependence', European Journal of History of Economic Thought, 7 (2), 171-80.

Arthur, B. (1989), 'Competing technologies, increasing returns, and lock-in by historical events', Economic Journal, 99, 116-31.

Boyer, R. (2005), 'Coherence, diversity, and the evolution of capitalisms: the institutional complementarity hypothesis', Evolutionary and Institutional Economic Review, 2 (1), 43-80. 
Chavance, B. and E. Magnin (2002), 'Emergence of path-dependent mixed economies in central Europe', in G. Hodgson (ed.), A Modern Reader in Institutional and Evolutionary Economics, Cheltenham: European Association of Evolutionary Political Economy, pp. 168-200.

Cowan, R. (1990), 'Nuclear power reactors: a study in technological lock-in', Journal of Economic History, 50, 541-67.

Cowan, R. (1996), 'Sprayed to death: path dependence, lock-in and pest-control strategies', Economic Journal, 106, 521-42.

Crouch, C. and H. Farrell (2004), 'Breaking the path of institutional development? Alternatives to the new determinism', Rationality and Society, 16 (1), 5-43.

David, P.A. (1975), Technical Choice, Innovation and Economic Growth: Essays on American and British Experience in the Nineteenth Century, Cambridge: Cambridge University Press.

David, P.A. (1985), 'Clio and the economics of Qwerty', American Economic Review, 75, 332-37.

David, P.A., (2001; 2007), 'Path dependence, its critics and the quest for "Historical Economics"', in P. Garrouste (ed.), Evolution and Path Dependence in Economic Ideas, Cheltenham, UK and Northampton, MA, USA: Edward Elgar. Also published in Hodgson, Geoffrey M. (ed.) (2007), The Evolution of Economic Institutions: A Critical Reader, Cheltenham, UK and Northampton, MA, USA: Edward Elgar, pp. 120-42.

David, P.A. (1990) 'Heroes, herds and hysteresis in technological history: Thomas Edison and the "Battle of the Systems" reconsidered', Journal of Industrial and Corporate Change, 1, 129-80.

David, P.A. (1994), 'Why are institutions the "carriers of history"? Path dependence and the evolution of conventions, organizations and institutions', Structural Change and Economic Dynamics, 5, pp. 205-20.

David, P.A. and M. Thomas (eds) (2003), The Economic Future in Historical Perspective, Oxford: Oxford University Press.

Denzau, A.T. and D.C. North (1994), 'Shared mental models: ideologies and institutions', Kyklos, 47 (1), 3-31.

Dixit, A.K. (1996), The Making of Economic Policy: A Transaction-Cost Politics Perspective, Cambridge, MA: MIT Press.

Dugger, W.M. (1993), 'Transaction cost economics and the state', in C. Pitelis (ed.), Transaction Costs, Markets and Hierarchies, Oxford: Basil Blackwell, pp. 188-216.

Frankel, M. (1955), 'Obsolescence and technological change in a maturing economy', American Economic Review, 45, 296-319.

Gartland M.P. (2005), 'Interdisciplinary views of sub-optimal outcomes: path dependence in the social and management sciences', The Journal of SocioEconomics, 34, 686-702.

Goldin, C. and G.D. Libecap (eds) (1994), The Regulated Economy: A Historical Approach to Political Economy, Chicago: University of Chicago Press.

Goldstone, J. (1998), 'Initial conditions, general laws, path dependence, and explanations in historical sociology', American Journal of Sociology, 104 (3), 829-45.

Greif, A. (2006), Institutions and the Path to The Modern Economy: Lessons from Medieval Trade, New York: Cambridge University Press.

Hedlund, S. (2005), Russian Path Dependence, London: Routledge.

Heiner, R.A. (1983), 'The origin of predictable behavior', American Economic Review, 73, 560-95. 
Hodgson, G.M. (1993), Economics and Evolution: Bringing Life Back into Economics, Cambridge: Polity Press.

Hodgson, G.M. (ed.) (1998), The Foundations of Evolutionary Economics, 18901973, Cheltenham, UK and Northampton, MA, USA: Edward Elgar.

Hodgson, G.M. (2007), The Evolution of Economic Institutions: A Critical Reader, Cheltenham, UK and Northampton, MA, USA: Edward Elgar.

Howell, C. (2005), Trade Unions and the State: The Construction of Industrial Relations Institutions in Britain, 1890-2000, Princeton, NJ: Princeton University Press.

Katz, M.L. and C. Shapiro (1994), 'Systems competition and network effects', Journal of Economic Perspectives, 8, 93-115.

Kindleberger, C.P. (1964), Economic Growth in France and Britain, 1851-1950, Cambridge, MA: Harvard University Press.

Krueger, A. (1996), 'The political economy of controls: American sugar', in L. Alston and T. Eggertsson (eds), Empirical Studies in Institutional Change, Cambridge: Cambridge University Press, pp. 125-53.

Langlois, R.N. and D.A. Savage (2001), 'Standards, modularity and innovation', in R. Garud and P. Karnoe (eds), Path Dependence and Creation, London: Lawrence Erlbaum Associates, pp. 149-68.

Lawson, T. (1997), Economics and Reality, London: Routledge.

Liebowitz, S.J. and S.E. Margolis (1995), 'Path dependence, lock-in, and history', The Journal of Law, Economics and Organisation, 11 (1), 205-26.

Magnusson, L. and J. Ottosson (1996), 'Transaction costs and institutional change: a case of the survival of the fittest?', in J. Groenewegen (ed.), Transaction Costs and Beyond, Boston, MA: Kluwer Academic Press, pp. 351-64.

Magnusson, L. (2001), 'The role of path dependence in the history of regulation', in L. Magnusson and J. Ottosson (eds), The State, Regulation and the Economy: An Historical Perspective, Cheltenham, UK and Northampton, MA, USA: Edward Elgar, pp. 107-19.

Magnusson, L. and J. Ottosson (eds) (2001), The State, Regulation, and the Economy: an Historical Perspective, Cheltenham, UK and Northampton, MA, USA: Edward Elgar.

Mahoney, J. (2000), 'Path dependence in historical sociology', Theory and Society, 29, 507-48.

Martin R. and P. Sunley (2006), 'Path dependence and regional economic evolution', Journal of Economic Geography, 6, 395-437.

Martin, R. and P. Sunley (2007), 'Complexity thinking and evolutionary economic geography', Journal of Economic Geography, 7 (5), 573-601.

Nelson, R.R. and S.G. Winter (1982), An Evolutionary Theory of Economic Change, Cambridge, MA: Belknap Press of Harvard University Press.

North, D.C. (1990), Institutions, Institutional Change and Economic Performance, Cambridge: Cambridge University Press.

North, D.C. (2005), Understanding the Process of Economic Change, Princeton, NJ: Princeton University Press.

Olson, M. (2000), Power and Prosperity: Outgrowing Communist and Capitalist Dictatorships, New York: Basic Books.

Ottosson, J. (2001), 'The state and regulatory orders in early European civil aviation', in L. Magnusson and J. Ottosson (eds), The State, Regulation and the Economy: An Historical Perspective, Cheltenham, UK and Northampton, MA, USA: Edward Elgar, pp. 148-66. 
Page, S. (2006), 'Essay: path dependence', Quarterly Journal of Political Science, 1, 87-115.

Pierson, P. (2000), 'Increasing returns, path dependence, and the study of politics', American Political Science Review, 94 (2), 251-67.

Pierson, P. (2004), Politics in Time: History, Institutions, and Social Analysis, Princeton, NJ: Princeton University Press.

Puffert, D.J. (2002), 'Path dependence in spatial networks: the standardization of railway track gauge', Explorations in Economic History, 39 (3), 282-314.

Puffert, D.J. (2003), 'Path dependence', EH.Net Encyclopedia, ed. Robert Whaples, 10 June, http://eh.net/encyclopedia/article/puffert.path.dependence, accessed 11 March 2008.

Ramstad, Y. (1994), 'On the nature of economic evolution: John R. Commons and the metaphor of artificial selection', in L. Magnusson (ed.), Evolutionary and Neo-Schumpeterian Approaches to Economics, Boston, MA, Dordrecht and London: Kluwer Academic Publishers, pp. 65-122.

Redding, S. (2002), 'Path dependence, endogenous innovation, and growth', International Economic Review, 43 (4), 1215-48.

Rosenberg, C. (1994), Exploring the Black Box, Cambridge: Cambridge University Press.

Rutherford, M. (1994), Institutions in Economics: The Old and the New Institutionalism, Cambridge: Cambridge University Press.

Scott, P. (2001), 'Path dependence and Britain's "Coal Wagon Problem" and the slow diffusion of high throughput technologies in inter-war British coal', Explorations in Economic History, 38, 366-85.

Scott, P. (2006) 'Path dependence, fragmented property rights mining', Business History, 48 (1), 20-42.

Streeck, W. and K.A. Thelen (eds) (2005), Beyond Continuity: Institutional Change in Advanced Political Economies, New York: Oxford University Press.

Vanberg, V. (1988), 'Rules and choice in economics and sociology', in E. Böttcher, P. Herder-Dorneich and K.-E. Schenk (eds), Jahrbuch für Neue Politische Ökonomie, vol. 7, Tübingen: Mohr Siebeck, pp. 146-67.

Vanberg, V. (1994), Rules and Choice in Economics: Essays in Constitutional Political Economy, London: Routledge.

Veblen, T. (1915), Imperial Germany and the Industrial Revolution, New York and London: Macmillan.

Vromen, J.J. (1995), Economic Evaluation: An Inquiry into the Foundation of New Institutional Economics, London: Routledge.

Williamson, O.E. (1996), The Mechanisms of Governance, New York: Oxford University Press.

Wilson, J.Q. (1989), Bureaucracy: What Government Agencies Do and Why They Do It, New York: Basic Books.

Witt, U. (2003a), The Evolutionary Perspective on Organizational Change and the Theory of the Firm, Jena: Max-Planck-Institute for Research into Economic Systems.

Witt, U. (2003b), The Evolving Economy: Essays on the Evolutionary Approach to Economics, Cheltenham, UK and Northampton, MA, USA: Edward Elgar. 